\title{
AVALIAÇÃO COMPARATIVA ENTRE OS MÉTODOS DE DESINFECÇÃO EMPREGANDO CLORO E OZÔNIO DE ÁGUAS DESTINADAS AO ABASTECIMENTO DE PEQUENAS COMUNIDADES
}

\author{
Wallace R. R. Lopes ${ }^{1}$ \\ Rafael M. S. Oliveira² \\ Juan C. V. Serra ${ }^{3}$
}

RESUMO: A busca por uma lógica social, ambiental e humanitária de que o acesso à água potável é um direito básico de todos esbarra muitas vezes em questões de viabilidade técnica e econômica no processo de tratamento da água, principalmente em países como o Brasil que possui território de proporções continentais e situação econômica e social heterogênea. As cidades de pequeno porte e as comunidades rurais, onde geralmente são necessárias tecnologias de desinfecção simples e de baixo custo, hoje se deparam com inexistência de sistemas de potabilização da água ou com sistemas de funcionamento intermitente e de desinfecção pouco confiável. Até recentemente não existiam alternativas de eficiência comprovada e custo competitivo em relação à cloração na desinfecção. Neste contexto, o ozônio ressurge como uma das principais alternativas na substituição do cloro. Por esse motivo, o presente artigo buscou apresentar, fundamentado na bibliografia atual, uma avaliação comparativa entre os métodos de desinfecção empregando cloro e ozônio de águas destinadas ao abastecimento de pequenas comunidades.

PALAVAS-CHAVE: Desinfecção. Cloro. Ozônio. Abastecimento. Pequenas comunidades.

\section{INTRODUÇÃO}


A água é essencial na vida do homem, mas ela precisa ser convenientemente tratada e ser submetida a um processo de desinfecção, pois quando ingerida pode ser responsável pela transmissão de muitas doenças como: amebíase; giardíase; gastroenterite; febres tifóide e paratifóide; hepatite infecciosa; cólera. A água também pode estar ligada à transmissão de algumas verminoses como a teníase, a esquistossomose, ascaridíase, ancilostomíase e oxiuríase.

Pensando na importância do acesso da sociedade a uma água microbiologicamente segura, foi publicada a Portaria MS 1469/2000 (Brasil, 2001) que estabeleceu que toda água fornecida coletivamente deve ser submetida a processo de desinfecção, concebido e operado de forma a garantir o atendimento ao padrão microbiológico. No entanto, o abastecimento público de água em termos de quantidade e qualidade é uma preocupação crescente da humanidade, em função da sua escassez e da deterioração da qualidade dos mananciais.

No livro intitulado Processos de Desinfecção e Desinfetantes Alternativos na Produção de Água Potável, que foi coordenado pelo Prof. Luiz Antonio Daniel, da Escola de Engenharia de São Carlos (EESC-USP), foram estudadas diferentes técnicas da desinfecção de águas com agentes químicos. O conjunto das pesquisas levou em consideração a heterogeneidade geográfica, econômica e social do país, nas diferentes regiões que precisam de soluções ou alternativas tecnológicas diferenciadas. Os autores alertam para problemas associados à inadequação dos sistemas de tratamentos, existentes há mais de 30 anos, considerando que a maioria deles foi implantada nos anos 1970, quando estava em vigência o Plano Nacional de Saneamento Básico (Planasa), sem maiores ampliações e aplicação de tecnologias mais modernas desde então. Dessa forma, sistemas de grande, médio e pequeno porte funcionam com sobrecarga, enfrentando problemas operacionais diversos associados à inadequabilidade da tecnologia escolhida com as características da água bruta.

Atualmente cerca de 30\% da população brasileira abastece-se de água proveniente de fontes inseguras, sendo que boa parte daqueles atendidos por rede pública nem 
sempre recebe água com qualidade adequada e em quantidade suficiente (COPASAD, 1996).

Diversas pequenas comunidades são abastecidas por poços rasos que captam água em aquíferos freáticos, bastante susceptíveis às contaminações. Na maioria dos casos, isto se deve em função da inexistência de redes coletoras de esgoto, acarretando o emprego extensivo de fossas negras e pela escavação e revestimentos inadequados dos poços.

Existe uma distribuição desigual do serviço entre regiões do país, entre a população urbana e a rural e ainda entre os municípios. $O$ acesso aos serviços de abastecimento de água decresce das Regiões Sudeste e Sul para as do Nordeste e Norte, tendo-se os menores índices nesta última. $\mathrm{O}$ acesso também diminui da população urbana para a rural e dos municípios de maior população para os de menor. Nas áreas urbanas a cobertura decai do centro para a periferia. Decai ainda dos ricos para os pobres (Opas b, 1998).

Essa conjuntura evidencia que os maiores problemas relacionados à qualidade da água destinada ao abastecimento público estão em locais menos populosos e mais remotos. As pequenas comunidades rurais são aquelas que mais possuem problemas relacionados ao acesso à água de qualidade.

Portanto, tendo em vista que atualmente o processo de desinfecção de água para fins de consumo humano em pequenas comunidades é deficiente, ou mesmo inexistente, e que há a importante necessidade de se analisar novas alternativas para 0 atual panorama Brasileiro de processos de tratamento e desinfecção de água, concebeu-se o presente artigo que procurou realizar, fundamentado na bibliografia atual, uma avaliação comparativa entre os métodos de desinfecção mais comuns, no caso àqueles empregando cloro e ozônio. 


\section{REVISÃO DE LITERATURA}

Os processos de desinfecção têm como objetivo a destruição ou inativação de organismos patogênicos, capazes de produzir doenças, ou de outros organismos indesejáveis (Cubillos, 1981).

Segundo Pádua (2009), da segunda metade do século XIX a primeira metade do século XX, o tratamento da água teve como objetivo central a clarificação e a remoção de organismos patogênicos, em torno do que foram se desenvolvendo as técnicas de desinfecção. As tecnologias convencionais de tratamento, visando a clarificação e desinfecção da água, foram sendo aprimoradas, incorporando novas técnicas ou variantes, tais como a flotação, a filtração direta, a filtração em múltiplas etapas, além do emprego de novos desinfetantes.

De acordo com Richter e Azevedo Netto (1991), entre os agentes da desinfecção (desinfetantes) o mais largamente empregado na purificação da água é o cloro, porque é facilmente disponível como gás, líquido ou sólido, é barato, é fácil de aplicar, deixa um residual em solução facilmente determinável e que protege o sistema de distribuição e é capaz de destruir a maioria dos microrganismos patogênicos. No entanto, apresenta algumas desvantagens, pois é um gás venenoso e corrosivo, requer cuidado no manejo e pode causar problemas de gosto e odor.

Nos EUA, a partir da década de 70, começaram a surgir evidências de incidência elevada de vários tipos de câncer (especialmente de bexiga, cólon e reto) em indivíduos com longa história de consumo de água clorada. A partir de 1975, foi descoberto que compostos organoclorados são cancerígenos e consequentemente o cloro começou a ter a sua aplicação cada vez mais limitada. Isto se deve à presença de determinados subprodutos das reações químicas do cloro com os compostos orgânicos contidos na água denominados trihalometanos. Em função das evidências dos problemas mencionados anteriormente e do surgimento de tecnologias alternativas de desinfecção 
com custo competitivo, observa-se atualmente, nos países de primeiro mundo, uma forte tendência de restrição de uso e substituição da cloração por tecnologias alternativas. Nesse contexto, o ozônio ressurgiu como uma das principais alternativas na substituição do cloro, resultando na retomada do desenvolvimento de aplicações de ozônio e principalmente dos sistemas de geração de ozônio (FRANCO et al., 2008; DOS SANTOS et al., 2011; LIMA et al., [s.d.])

Di Bernardo (2003) também diz que a necessidade do controle de trihalometanos e de outros subprodutos indesejados da cloração incentivou o desenvolvimento de pesquisas envolvendo outros oxidantes, a fim de substituir o cloro na oxidação das águas de abastecimento público. Dentre os principais, o ozônio tem sido utilizado extensivamente como oxidante e desinfetante em tratamento de águas superficiais para a produção de água potável na Europa, e está cada vez mais sendo aplicado como préoxidante nos Estados Unidos, substituindo a pré-cloração.

O ozônio não tem sido muito utilizado no Brasil, mas tem sido empregado na Europa e nos EUA desde o final do século XIX, para desinfecção e oxidação de água de abastecimento público. Nos EUA o ozônio é um dos oxidantes e desinfetantes mais efetivos usado em tratamento de água, necessita de menor tempo de contato, porém sua ação desinfetante se dá por meio do residual de oxigênio molecular remanescente, o qual é instável e raramente encontrado na água após alguns minutos do ozônio ter sido aplicado. O ozônio decompõe-se espontaneamente na água por meio de mecanismos complexos que envolvem a geração de radicais livres hidroxilas $(\cdot \mathrm{OH})$, os quais são muito reativos (DANIEL et al, 2001).

A habilidade do ozônio para desinfecção de água foi descoberta em 1886 e em 1891 testes pilotos já eram realizados em Martinkenfelde, na Alemanha. No entanto, a primeira instalação de ozônio em escala industrial ocorreu em 1893, em Oudshoorm, na Holanda, objetivando a desinfecção de água na estação de tratamento de água potável desta cidade. Passou a ser utilizado comercialmente em 1903 para tratamento de água potável (DE OLIVEIRA-SOUZA et al., 2000). 
O cloro é, historicamente, o método mais utilizado de desinfecção da água sendo ele possuidor de elevado potencial de oxidação. É extremamente eficaz na desinfecção e de relativa facilidade no manuseio e dosagem, tendo além disso custo relativamente baixo.

Vale ressaltar as razões que culminaram com a disseminação do cloro e seus compostos como desinfetantes a partir do início do século XX. Podem ser destacadas, entre outras (BRASIL, 2006):

- Inativação em tempo relativamente curto dos micro-organismos até então conhecidos, presentes nas águas naturais;

- Nas dosagens usualmente empregadas na desinfecção, o cloro não e toxico aos seres humanos e não confere odor ou sabor as águas;

- Disponível a custo razoável e de fácil transporte, manuseio, armazenamento e aplicação;

- Produção de residuais relativamente estáveis;

- Fácil determinação pelo método iodométrico disponível a época.

Para HELLER, L., DE PÁDUA (2006), até recentemente não existiam alternativas de eficiência comprovada e custo competitivo em relação à cloração na desinfecção, além disso não se conheciam desvantagens ou riscos sérios associados ao uso do Cloro, desde que respeitados os procedimentos de segurança indicados para o transporte, manuseio e armazenagem; e as dosagens habituais. Não obstante, vale mencionar alguns dos problemas habitualmente associados à cloração:

- Todas as formas de Cloro são fortemente corrosivas e tóxicas, as instalações de cloração exigem constante supervisão pelo operador, e constantes manutenções; 


\section{Then \\ Fórum Ambiental \\ da Alta Paulista}
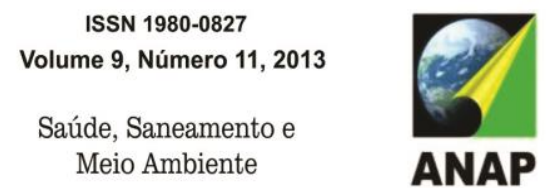

ANAP

- Vapores originários de vazamentos de cloro gasoso ou do contato de tabletes/granulados com umidade são extremamente tóxicos, podendo serem letais;

- O cloro e/ou os seus subprodutos podem conferir sabor desagradável à água e reduzir seu $\mathrm{pH}$;

- Determinados subprodutos da cloração, tais como cloraminas e clorofenóis, são tóxicos e podem impactar negativamente sobre a fauna aquática de corpos receptores de esgotos;

Pesquisas têm mostrado que a reação do cloro com algumas substâncias, principalmente substâncias húmicas, leva a formação de trihalometano, compostos organoclorados que podem causar problemas à saúde humana. Contudo, os riscos sanitários, eventualmente associados a subprodutos da cloração, podem ser muito menores do que aqueles decorrentes das doenças de veiculação hídrica a que a população estará sujeita, caso a água não seja submetida a algum processo de desinfecção.

Meyer (1994) também diz que deve ser enfatizado que os THM não são o único risco existente em relação à cloração das águas. Em função dos compostos orgânicos presentes na água bruta, outros subprodutos da cloração, mais perigosos que os THM, podem ser formados.

LIMA, Erlon e KOLLNBERGER (2009) sustentam que o ozônio, quando aplicado na água, age como potentíssimo oxidante de contaminantes, produzindo moléculas inócuas precipitadas, gerando oxigênio como subproduto. A ação do Ozônio é extremamente rápida $(<1 / 10 \mathrm{~s}$ ) e não-seletiva (mata todos micro-organismos: bactérias, fungos, bolores, vírus, etc.). Para os autores o ozônio possui as seguintes característias:

- Reduz metais à suas formas insolúveis (normalização);

- Destrói hidrocarbonetos por dissociação (quebra das cadeias); 


\section{Then \\ Fórum Ambiental \\ da Alta Paulista}
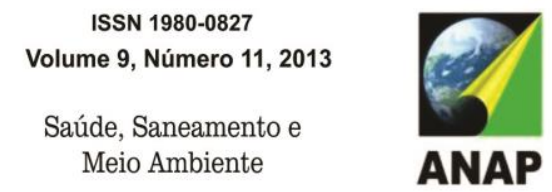

- Solidifica (mineraliza) compostos orgânicos dissolvidos causando a sua coagulação e precipitação;

- Eleva o potencial redox da água, causando microfloculação (microprecipitação) dos patogênicos e pirógenos destruídos, que podem facilmente ser removidos por filtração;

- Não deixa residual remanescente na água devido o tempo de reação ser reduzido.

Segundo HELLER \& PÁDUA (2006), o ozônio está entre os desinfetantes alternativos que mais tem sido utilizado nas ETA's, em substituição ao cloro gasoso. $O$ residual de ozônio na água é pouco persistente, enquanto o dióxido de cloro é bastante estável, o que é extremamente vantajoso, para prevenir eventuais contaminações que podem ocorrer no sistema de abastecimento de água.

Na Portaria no 518/2004 do Ministério da Saúde (Brasil, 2004), é estabelecido que após a desinfecção, a água deve conter um teor mínimo de cloro residual livre de 0,5 $\mathrm{mg} / \mathrm{L}$, sendo obrigatória a manutenção de, no mínimo, $0,2 \mathrm{mg} / \mathrm{L}$ em qualquer ponto da rede de distribuição.

Em meio ostensiva oposição da sociedade à cloração das águas para fins de abastecimento, a adoção dessa metodologia foi imposta em algumas cidades. Após, foi comprovado na cidade de São Paulo que a incidência de doenças intestinais apresentou uma significativa redução a partir introdução da cloração como método de desinfecção. Por outro lado, a técnica adotada não previa a aplicação de cloro em quantidades que superassem a manutenção de um residual dosável após 60 minutos (RICHTER \& NETTO, 1998).

Para Zarpelon e Rodrigues (2002), a principal dificuldade de implementação da ozonização para tratamento de água é a impossibilidade de o ozônio produzir residual que previna eventual contaminação do sistema de distribuição de água. 
Entretanto, o forte poder oxidante do cloro torna-o útil para outras finalidades como o controle de sabor e odor, remoção de sulfeto de hidrogênio, ferro e manganês, remoção de cor, etc. O ozônio é o desinfetante competidor mais próximo do cloro, sendo utilizado em larga escala na Europa (RICHTER \& NETTO, 1998).

Sanches et al. (2003) concluiu que qualquer que seja o desinfetante alternativo, deve-se garantir que: a) seja efetivo na inativação de bactérias, vírus e protozoários, entre outros organismos patogênicos; b) sua aplicação seja confiável e feita por meio de equipamentos simples, tendo em vista o grau de desenvolvimento socioeconômico da comunidade; c) não produza qualquer composto secundário que cause risco à saúde pública; d) apresente atributos similares ao do cloro, tais como fornecer resíduos persistentes na água; e) tenha sua concentração facilmente medida, não acarrete sabor e odor, e seja disponível no mercado a custos razoáveis.

Sanches et al. (2003) prevê que futuramente, os desinfetantes não clorados deverão ser crescentemente utilizados, de forma combinada e até substitutiva ao cloro, de acordo com o desenvolvimento socioeconômico da comunidade e com os custos envolvidos no tratamento de água.

\section{CONCLUSÕES}

A cloração tem sido tão extensamente utilizada no Brasil como desinfetante, que os termos cloração e desinfecção acabam se confundindo na prática, o que é preocupante, pois deve ser uma premissa da fase de concepção de projetos de tratamento de água a consideração do máximo de alternativas tecnológicas existentes. No caso da decisão de qual via de desinfecção será utilizada em uma instalação de tratamento de água, o ozônio não deveria ser visto apenas como uma alternativa para o uso do cloro, mas sim como alternativa adequada e conveniente para qualquer concepção de projeto, e mais ainda 
para aquelas de pequenas comunidades. Isto por que houve um significativo o avanço recente nas pesquisas de novas tecnologias relacionadas ao uso do ozônio no tratamento de água para fins de abastecimento.

Por outro lado, obviamente não se deve perder de vista que a concepção de uma instalação de abastecimento de água, ainda que para atendimento a uma pequena comunidade, requer a avaliação de diversos outros fatores como características físicas, socioeconômicas e demográficas.

De fato, muitos autores dizem que a manutenção residual do cloro na água é uma importante vantagem por impedir contaminações posteriores, no entanto, para pequenas comunidades, onde a rede de distribuição é considerada pequena e passível de controle e manutenção muito mais efetivo, essa vantagem se torna refutável. Ademais, deve ser considerada a possibilidade de um processo interativo, ou combinado entre as duas alternativas de desinfecção, pois, com o uso do ozônio como principal desinfetante, o cloro passa a ser utilizado em quantidades menores, o que reduz a possibilidade de formação de subprodutos, gosto e odor na água, além de custos, em médio-longo prazo.

Uma das mais importantes justificativas para a manutenção do uso do cloro como agente desinfetante em pequenas comunidades ainda está no custo envolvido. Mas, por outro lado, empresas têm investido em estudos e desenvolvimento de equipamentos que produzem ozônio como alternativa de desinfecção de pequena escala, buscando com sucesso, principalmente a simplificação e redução custo de implantação e operacionalização.

\section{REFERÊNCIAS}


BRASIL. Ministério da Saúde. Secretaria de Vigilância em Saúde. Vigilância e controle da qualidade da água para consumo humano. Ministério da Saúde, Secretaria de Vigilância em Saúde. Brasília: Ministério da Saúde, 2006. 212 p.

COPASAD. Conferencia pan-americana sobre saúde e ambiente no desenvolvimento humano sustentável. Plano Nacional de Saúde e Ambiente no Desenvolvimento Sustentável. Brasília: Ministério da Saúde, 1995.

CUBILLOS, A., 1981. Calidad y Control de La polucion del Agua. Mérida: CIDIAT/Centro Interamericano de Desarollo Integral de Aguas y Tierras. (Mimeo.) (Série Ambiente y Recursos Naturales Renovables, AR 14).

DANIEL, L.A. et al. Processos de desinfecção e desinfetantes alternativos na produção de água potável. cap. 2. ABES-PROSAB. Rio de Janeiro, RJ. 2001.

DE OLIVEIRA-SOUZA, A. O.; SILVA, M. A. S.; MACHADO, S. A. S.: AVACA, L. A.; LIMA NETO, O. P. Influence of the preparation method on the morphologic and eletrochemical properties of Ti//rO ${ }_{2}$-Coated Electrode. Electrochim. Acta, v45, p. 4467-4473, 2000.

DI BERNARDO, L. (coordenador). (2003). Tratamento de água para abastecimento por filtração direta, ABES, RiMa, Rio de Janeiro.

HELLER, L., DE PÁDUA, V.L. Abastecimento de água para consumo humano. Editora UFMG. 2006.

LIMA, Erlon; KOLLNBERGER, Gerhard. Tecnologias modernas para desinfecção de água e esgoto. Parte 2: desinfecção por ozonização. São Paulo: Proquim, [s.d.] Disponível em: <http://www.proquimuv.com.br/fr_artigos.htm> Acesso em 19 jun. 2013.

LIMA, Erlon; KOLLNBERGER, Gerhard. Tecnologias modernas para desinfecção de água e esgotos - parte 1 - desinfecção por irradiação uv. São Paulo : Proquim, [s.d.] Disponível em: <http://www.proquimuv. com.br/fr_artigos.htm> Acesso em 19 jun. 2013. 
MEYER, Sheila T. O uso de cloro na desinfecção de águas, a formação de trihalometanos e os riscos potenciais à saúde pública. Cad. Saúde Pública, Mar 1994, vol.10, no.1, p.99110.

OPAS. Organizacao Pan-Americana da Saude. Cenário do saneamento básico no Brasil: um enfoque sobre as áreas atingidas pela seca e pelo Projeto para Redução da Mortalidade na Infância - PRMI. Brasília: Opas, 1998b.

PÁDUA, V. L. (Coord). Remoção de microoganismos emergentes e microcontaminantes orgânicos no tratamento de água para consumo humano. Rio de Janeiro: ABES, 2009.

RICHTER Carlos A., AZEVEDO NETO José M. de. Tratamento de Água. Tecnologia atualizada, Editora Edgard Blücher Ltda, São Paulo - SP, pág. 1, 1991.

SANCHES, Sérgio et al. Agentes desinfetantes alternativos para o tratamento de água. Revista Química Nova na Escola, no 17, p.8-12, maio, 2003.

ZARPELON, A.; RODRIGUES, E. M. (2002). Os trihalometanos na água de consumo humano. Sanare. Revista técnica da Sanepar, v. 17, n. 17, p. 20-30. 